\title{
EL DERECHO DE SEPARACIÓN POR FALTA DE DISTRIBUCIÓN DE DIVIDENDOS EN EL DERECHO DE SOCIEDADES ESPAÑOL
}

RIGHT OF EXIT DUE TO FAILURE TO DISTRIBUTE DIVIDENDS IN SPANISH COMPANY LAW

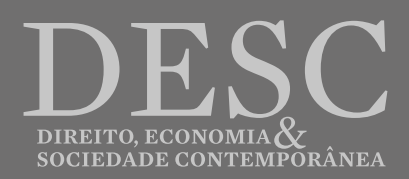




\title{
EL DERECHO DE SEPARACIÓN POR FALTA DE DISTRIBUCIÓN DE DIVIDENDOS EN EL DERECHO DE SOCIEDADES ESPAÑOL
}

\author{
RIGHT OF EXIT DUE TO FAILURE TO DISTRIBUTE \\ DIVIDENDS IN SPANISH COMPANY LAW
}

\section{MIGUEL MARTÍNEZ MUÑ̃̃Z \\ Universidad Pontificia Comillas ICAI-ICADE

\begin{abstract}
Resumen: este trabajo pretende analizar el derecho de separación en el Derecho de Sociedades español, el cual se presenta en nuestro ordenamiento jurídico como el mecanismo de defensa natural que tienen los socios en las sociedades de capital frente a la opresión y al abuso de derecho ejercitado por los socios mayoritarios, así como la regulación establecida para el caso concreto de la falta de distribución de dividendos. La configuración actual del derecho de separación presenta ineficiencias en la medida en que las causas legales y estatutarias de separación no son suficientes para cubrir todos los supuestos que pueden presentarse, siendo necesario abordar esta problemática.
\end{abstract}

Palabras clave: derecho de separación, opresión, abuso de derecho, causas legales, causas estatutarias, distribución de dividendos, separación por justa causa.

\begin{abstract}
Spanish Company Law. This right constitutes the natural defence mechanism owned by the shareholders in the public and private companies in order to fight against oppression and abuse of law practised by the majority shareholders, as well as the regulation established for the specific case of the lack of dividend distribution. The current configuration of the right of exit presents inefficiencies because the legal and statutory causes of exit are not sufficient to resolve all the events that may arise and it is necessary to address this problem.
\end{abstract}

Keywords: right of exit, oppression, abuse of law, legal causes, statutory causes, distribution of dividends, exit for a just cause. 


\section{INTRODUCCIÓN}

El derecho de separación constituye un mecanismo de protección del socio minoritario frente a determinadas conductas realizadas por los socios mayoritarios y que son, a priori, constitutivas de comportamientos abusivos ${ }^{1}$. En este sentido, podemos definir tal instituto como el derecho del socio a abandonar la sociedad de capital, siempre que concurra una causa legal o estatutaria habilitante, con devolución de la cuota correspondiente y sin que, en ningún caso, tenga lugar la disolución de aquélla²

Este derecho ya venía reconocido en la Ley de Sociedades Anónimas de 1951 y de 1989, en contraposición a lo que ocurría en la Ley de Sociedades de Responsabilidad Limitada de 1953, la cual omitía toda referencia al derecho de separación por considerar la no existencia de conflictos en este tipo de sociedades ${ }^{3}$. El legislador, consciente de su error de concepción, corrigió este extremo en la Ley de Sociedades de Responsabilidad Limitada de 1995 y lo ha mantenido en la vigente Ley de Sociedades de Capital (en adelante, la "LSC") y en la Ley de Modificaciones Estructurales para el caso del derecho de separación en relación con las modificaciones estructurales. Antes ya se preveía en el Código de Comercio, con carácter general y de manera muy limitada para las sociedades personalistas, la salida de un socio realizada al ejercitar el derecho de separación o producida como consecuencia de su baja en la sociedad a causa de su rescisión parcial, situación que permanece inalterada actualmente ${ }^{4}$.

La mecánica del derecho de separación afecta a tres sujetos diferentes. Por un lado, afecta al propio socio disidente, el cual ejercita el derecho de separación ante la concurrencia de alguna de las causas legales o estatutarias de separación previstas como vía de escape de la sociedad ${ }^{5}$. En segundo lugar, afecta a la propia sociedad, la cual deberá reducir su capital social conforme a lo previsto en el art. 358 LSC. Por último, el ejercicio del derecho de

1 Garrigues, J/Uría, R. 1953. Comentario a la Ley de Sociedades Anónimas. Tomo II. Madrid. p. 202, donde se califica este derecho, siguiendo a la doctrina italiana, como el arma más eficaz de defensa de la minoría contra los excesos de la mayoría.

2 Brenes Cortés, J. 1999. El derecho de separación del accionista. Madrid. p. 26; Farrando Miguel, I. 1998. El derecho de separación del socio en la Ley de Sociedades Anónimas y la Ley de Sociedades de Responsabilidad Limitada. Madrid. pp. 7172; Girón Tena, J. 1952. Derecho de Sociedades Anónimas (Según la Ley de 17 de julio de 1951). Valladolid. p. 468; Motos Guirao, M. 1956. La separación voluntaria del socio en el Derecho Mercantil español. Revista de Derecho Notarial. 11:81-83; Velasco Alonso, A. 1976. El derecho de separación del accionista. Madrid. p. 11; González Castilla, F. 2012. Reformas en materia de separación y exclusión de socios. In Farrando Miguel, I, González Castilla, F, Rodríguez Artigas, F, editors. Las reformas de la Ley de Sociedades de Capital. Cizur Menor. pp. 312-313; Emparanza, A. 2011. Artículo 346. Causas legales de separación. in Rojo, A, Beltrán, E, editors. Comentarios a la Ley de Sociedades de Capital. Cizur Menor. p. 2470.

3 Sobre las antecedentes de esta figura véase, entre otros, Rodas Paredes, P. 2013. La separación del socio en la Ley de sociedades de capital. Madrid. pp. 21-28.

4 Sequeira Martín, A. 2011. Derecho de separación y la exclusión del socio. Revista de Derecho de Sociedades. 36:190.

5 Podemos decir que el contrato de sociedad (Paz-Ares, C. 2006. La sociedad en general: caracterización del contrato de sociedad. In Uría, R, Menéndez, A. Curso de Derecho Mercantil. Tomo I. Cizur Menor. p. 470) presenta dos rasgos sobresalientes: su aptitud para organizar una actividad empresarial con vocación de permanencia en el tráfico económico (es un contrato de duración) y, por otro lado, su carácter incompleto. Por su parte, el carácter incompleto de un contrato se predica cuando concurren dos rasgos: (i) no se prevén inicialmente todos los derechos y obligaciones de las partes para todas las futuras contingencias, y (ii) se establecen ciertas mecánicas para afrontarlas (vid. Alfaro Águila-Real, J. 2005. Los problemas 
separación afectará a los acreedores sociales, los cuales verán las posibilidades de satisfacción de sus créditos mermadas ante la disminución del patrimonio social ${ }^{6}$.

La propia configuración de las sociedades de capital, en el sentido del establecimiento de unos órganos sociales responsables de la toma de decisiones, conduce a la pérdida de autonomía del socio individual en los asuntos de carácter común y la supremacía del principio de adopción de acuerdos por mayoría, el cual será utilizado por los socios mayoritarios para generar situaciones constitutivas de abuso de derecho sobre la minoría en determinados aspectos de la vida social, materializándose así unos conflictos permanentes entre los socios $^{7}$. No obstante, dicho principio no puede tener un carácter absoluto con la consiguiente desprotección jurídico-societaria. Los intereses individuales del socio y los intereses de la minoría gozan de diversos mecanismos de protección, entre los que destaca el ejercicio, por parte del socio, del derecho de separación que le atribuye el ordenamiento jurídico ${ }^{8}$.

Si bien el abuso de la mayoría se produce tanto en las sociedades anónimas como en las limitadas, es claro que aquel es más intenso en las sociedades de responsabilidad limitada debido a la propia configuración de este tipo social ${ }^{9}$. Se trata de una sociedad en la que sólo concurre el modelo de socio interesado en la vida de la empresa (y no el interesado únicamente en rentabilizar su inversión con dividendos y aumentos en la cotización de las acciones propio de las sociedades anónimas), con una mayoría compacta y permanente y la existencia de una serie de restricciones para la entrada y salida en el capital social, todo lo cual provoca que la opresión al socio minoritario sea, en este caso, muy intensa.

La Ley de Sociedades de Responsabilidad Limitada de 1953 no preveía ningún sistema de protección a los socios minoritarios y ello porque, según su Preámbulo, en este tipo social "no existe problema de defensa de minorías, a diferencia de lo que ocurre en la S.A.". Como apuntábamos antes, la propia configuración de la sociedad limitada hacía pensar al legislador de 1953 que los pocos socios integrantes de este tipo social tenían exactamente los mismos intereses

contractuales en las sociedades cerradas. Indret: Revista para el análisis del Derecho. 4:3; Alfaro Águila-Real, J. 1995. Interés social y derecho de suscripción preferente. Madrid. p. 23; Farrando Miguel, I. p. 48).

6 Farrando Miguel, I. p. 21.

7 Fernández del Pozo, L. 2006. La arbitrabilidad de un derecho estatutario de separación por "justa causa" en una Sociedad Anónima. En torno a la STC 9/2005, de 17 de enero de 2005. Revista de Derecho de Sociedades. 26:269-272; Martínez Calcerrada, L. 1979. La buena fe y el abuso del derecho. Su respectiva caracterización como límites en el ejercicio de los derechos. Revista de Derecho Privado. 1979:434 y ss; Ginés Castellet, N. 2013. Impugnación de acuerdos sociales y abuso de derecho: algunas reflexiones para el ordenamiento jurídico español a la luz de la experiencia francesa. Revista de Derecho de Sociedades. 40: 274 y ss.

8 Para el estudio de los diversos intereses societarios en juego, vid. Sánchez Ruiz, M. 2000. Conflictos de Intereses entre Socios en Sociedades de Capital. Elcano. pp. 32-34; Alcalá Díaz, MA. 1997. El conflicto de intereses socio-sociedad en las sociedades de capital. Revista de Derecho de Sociedades. 9:89 y ss.

9 Pulgar Ezquerra, J. 2013. Reestructuración de sociedades de capital y abuso de minorías. Revista de Derecho Bancario y Bursátil. 129:29-34. 
y que, por ello, no existían problemas entre los socios ${ }^{10}$. Sin embargo, las características de la sociedad limitada hacen que la dominación al minoritario sea aún más opresiva, teniendo éste muy pocas posibilidades de solución. En efecto, la opresión en este tipo social se torna aún más intensa si tenemos en cuenta que la sociedad de responsabilidad limitada es la sociedad modelo de las sociedades cerradas, caracterizadas por la imposibilidad fáctica de desinvertir al ser el mercado para la transmisión de las participaciones sociales extremadamente reducido y por existir un grupo de control estable que, con base en el principio de adopción de acuerdos por mayoría, toma las decisiones sin tener en cuenta los intereses del socio minoritario, el cual no puede enajenar su cuota y abandonar el panorama social ${ }^{11}$.

Por ello, una de las posibles vías de solución de estos conflictos intrasocietarios es el derecho de separación, institución singular y de encaje violento en un sistema de estructura corporativa sometido al principio de adopción de acuerdos por la mayoría, ya que casa mal con el reconocimiento de un derecho de separación al socio por el solo hecho de no haber contribuido con su voto a la adopción de un determinado acuerdo ${ }^{12}$. El derecho de separación, ante todo, pretende proteger al socio minoritario del abuso de la mayoría que se produce en las sociedades cerradas a través de múltiples actuaciones, siendo una muy común la asfixia financiera en forma de retención sistemática de dividendos. En efecto, en tanto es la Junta de socios la que mayoritariamente acuerda el reparto de dividendos a la hora de aprobar las cuentas formuladas por los administradores, la minoría tiene poco margen de actuación si cada año se decide destinar la totalidad del beneficio a reservas. Precisamente, para evitar esta forma concreta de abuso, el legislador introdujo el art. 348 bis LSC y concedió un derecho de separación para el supuesto de que no se repartiera como dividendo una determinada parte del beneficio, norma que actualmente se encuentra en vigor después de un largo período de suspensión.

\section{FUNDAMENTO DEL DERECHO DE SEPARACIÓN DEL ART. 348 BIS LSC}

El art. 348 bis LSC es un precepto que fue introducido en nuestro ordenamiento a través de la Ley 25/2011, de 1 de agosto, de reforma parcial de la Ley de Sociedades de Capital y de incorporación de la Directiva 2007/36/CE, del Parlamento Europeo y del Consejo, de 11 de julio, sobre el ejercicio de determinados derechos de los accionistas de

10 Carlón, L. 1978. Reflexiones sobre la tutela de la minoría en la Sociedad de responsabilidad limitada. In Estudios de Derecho Mercantil en homenaje a Rodrigo Uría. Madrid. pp. 83-84.

11 En este sentido, Sánchez Ruiz, M. p. 39.

12 Martínez Sanz, F. 1997. La separación del socio en la sociedad de responsabilidad limitada. Madrid. pp 3-4; Farrando Miguel, I. pp. 59-60: “(...) es también necesario añadir que éste (el derecho de separación) no es un remedio diseñado por el legislador para combatir los acuerdos ilícitos, para conocer el valor real de las acciones o participaciones o, como indicamos antes, un instituto que excepcione el principio de adopción de acuerdos societarios por mayoría o el principio de subordinación a los acuerdos sociales sino, más concretamente, un instrumentos de conciliación ante los casos de divergencia de intereses entre el socio, aisladamente considerado, y la colectividad". 
sociedades cotizadas. En concreto, la norma disponía: "A partir del quinto ejercicio a contar desde la inscripción en el Registro Mercantil de la sociedad, el socio que hubiera votado a favor de la distribución de los beneficios sociales tendrá derecho de separación en el caso de que la junta general no acordara la distribución como dividendo de, al menos, un tercio de los beneficios propios de la explotación del objeto social obtenidos durante el ejercicio anterior, que sean legalmente repartibles".

Se introducía pues un específico derecho de separación ad hoc a favor del socio que hubiera votado a favor de la distribución de beneficios, de tal suerte que, en paralelo, parecía que se confería un derecho concreto a percibir un porcentaje legal mínimo y un correlativo deber de la Junta de acordar, en todo caso, con independencia de la situación económica, una distribución como dividendo de, al menos, un tercio de los beneficios propios de la explotación del objeto social ${ }^{13}$. Sin embargo, dadas las dificultades económicas y financieras que experimentaban las empresas en los años 2011 y 2012 14 , la norma fue dejada en suspenso hasta el 31 de diciembre de 2014 en virtud de la Ley 1/2012, de 22 de junio, de simplificación de las obligaciones de información y documentación de fusiones y escisiones de sociedades de capital. De nuevo, se prorrogó la suspensión hasta el 31 de diciembre de 2016 por la disposición transitoria primera de la LSC, modificado por la disposición final primera del RD Ley 11/2014, de 5 de septiembre, de medidas urgentes en materia concursal. En consecuencia, desde el 1 de enero de 2017, el art. 348 bis LSC vuelve a estar plenamente operativo y de acuerdo a su redacción original, la cual ya había planteado numerosos problemas de interpretación que hoy vuelven a ser puestos de manifiesto ${ }^{15}$.

A pesar de la importancia que tiene la concesión de este mecanismo de la separación como forma de atajar la política sistemática de no reparto de dividendos, la cual se erige en

13 Véase en profundidad Pulgar Ezquerra, J. 2017. Reparto legal mínimo de dividendos: protección de socios y acreedores (solvency test). Revista de Derecho Bancario y Bursátil. 147:143-144.

14 Con respecto a los problemas que podían surgir en sede de sociedades que se encontraban en procesos de financiación y refinanciación si se ejercitaba por un socio el derecho de separación del art. 348 bis LSC, véase García Morales E/Jiménez López, L. 2018. ¿Es compatible el artículo 348 bis con las restricciones al reparto de dividendos previstas en determinados contratos de financiación? Diario La Ley. 9150:1-13. En el mismo sentido, véase Alonso Ledesma, C. 2013. La autonomía de la voluntad en la exclusión y separación de socios. Revista de Derecho Mercantil. 287:91, donde se afirma que el ejercicio del derecho de separación puede poner en peligro la viabilidad empresarial al suponer una salida de fondos que son muy necesarios en estos tiempos críticos para reforzar la situación financiera de la empresa o para financiar nuevos proyectos empresariales que pueden suponer cuantiosos beneficios futuros. Además, la autora pone de manifiesto cómo la falta de claridad del precepto y el rigor con que se obliga al reparto anual, de, al menos, un tercio de los beneficios de la explotación, ha desatado el rechazo de parte de la doctrina que ha criticado duramente la norma, no sólo porque su defectuosa redacción vaya a dar lugar a multitud de dudas interpretativas para su aplicación, sino porque la norma vulnera la competencia de la Junta para decidir acerca de la aplicación del resultado del ejercicio.

15 Véase Martínez Muñoz, M. 2015. El derecho de separación del socio en las sociedades de capital y su regulación en el Anteproyecto de Ley de Código Mercantil. CEF Legal: Revista Práctica de Derecho. 175-176:29-34; Brenes Cortés, J. 2017. El derecho de separación en caso de falta de distribución de dividendos: la entrada en vigor del controvertido artículo 348 bis de la Ley de Sociedades de Capital. Revista de Derecho Mercantil. 305:50 y ss.; Cañabate Pozo, R. 2017. La defensa del socio minoritario por falta de distribución de dividendos. Revista de derecho de Sociedades. 50:171 y ss.; Pulgar Ezquerra, J. 2017. pp. 149 y ss., 
una de las principales formas de opresión a la minoría, hemos de destacar que el art. 348 bis LSC no apela en ningún momento a los conceptos de opresión o abuso de mayoría, sino que se limita a establecer un derecho que puede ser ejercitado tras cada Junta General ordinaria en la que no se apruebe el reparto de dividendos, lo que resulta criticable en tanto en cuanto no consagra los desarrollos jurisprudenciales en la materia basados en el abuso de derecho ${ }^{16}$. A este respecto, hubiera sido deseable que la norma en cuestión recogiese y concretase la jurisprudencia recaída en materia de abuso de derecho y que, incluso, hubiera sido redactada en términos más amplios para que diera cabida a más comportamiento abusivos ${ }^{17}$. Sin embargo, el fundamento del art. 348 bis LSC es claro en tanto no pretende resolver todas las posibles formas de abuso de mayoría sino únicamente la consistente en la asfixia financiera, tutelando los intereses de aquellos socios minoritarios que no están recibiendo la oportuna y legítima rentabilidad que cabría esperar del contrato de sociedad.

Por lo que respecta a la ubicación sistemática de este precepto, el mismo se trata de una causa legal de separación adicional a las enumeradas en el art. 346 LSC. En efecto, para que el socio pueda ejercitar el derecho de separación que le dispensa el ordenamiento jurídico-societario es preciso que concurra una causa de separación, la cual podrá ser legal, si se encuentra en el elenco de supuestos dados por el legislador en la LSC, o estatutaria, si los socios han decidido en la fundación de la sociedad o posteriormente, a través de la oportuna modificación, añadir causas de separación adicionales a las contenidas en la Ley. Así pues, la falta de distribución como dividendo de, al menos, un tercio de los beneficios propios de la explotación del objeto social obtenidos durante el ejercicio anterior, que sean legalmente repartibles, en aquellas sociedades de capital no cotizadas y a partir del quinto ejercicio desde su inscripción en el Registro Mercantil, aparece configurada como una causa legal de separación al venir expresamente prevista por el legislador en el art. 348 bis LSC ${ }^{18}$. A pesar de esta configuración, el legislador no introdujo el nuevo supuesto dentro del art. 346 LSC,

16 Por ejemplo, la Sentencia del Tribunal Supremo de 7 de diciembre de 2011, en la que se pone de manifiesto que: “(...) los acuerdos de la mayoría que no persiguen razonablemente el interés del conjunto de los accionistas desde la perspectiva contractual, ni los de la sociedad, desde la perspectiva institucional, y perjudican a los minoritarios, revelándose abusivos -tanto si se califica el ejercicio del voto como abuso de derecho, como si se entiende que constituye un abuso de poder-deben entenderse contrarios a los intereses de la sociedad, cuyo regular funcionamiento exige también el respeto razonable de los intereses de la minoría, de tal forma que, aunque el artículo 115.1 de la Ley de Sociedades Anónimas, aplicable para la decisión del recurso por razones temporales -hoy 204.1 de la Ley de Sociedades de Capital-silencia el "abuso de derecho" y el "abuso de poder", ello no constituye un obstáculo insuperable para la anulación de los acuerdos sociales en tales supuestos, ya que, a tenor del artículo $7 \mathrm{del} \mathrm{Código} \mathrm{Civil,} \mathrm{son} \mathrm{contrarios} \mathrm{a} \mathrm{la} \mathrm{ley-en} \mathrm{este} \mathrm{sentido} \mathrm{apuntan} \mathrm{las} \mathrm{sentencias} \mathrm{de} 10$ de febrero de 1992, 1136/2008 10 de diciembre, y 770/2011, de 10 de noviembre".

17 González Castilla, F. p. 328. Por su parte, García Sanz, A. 2012. Derecho de separación en caso de falta de distribución de dividendos. Revista de Derecho de Sociedades. 38: 55-71. Hernando Cebriá, L. 2011. Del socio de control al socio tirano y al abuso de la mayoría en las sociedades de capital. Revista de Derecho de Sociedades. 37:173-205, señalan que nuestra jurisprudencia ha apuntado que la protección del derecho del socio a participar en el reparto de las ganancias sociales se construye desde la figura del abuso de derecho.

18 Alonso Ledesma, C. pp. 91-92: “(...) el reconocimiento del derecho de separación por falta de pago de dividendos, que el legislador ha tipificado, con más que discutible fortuna, como una nueva causa legal de separación (...)”; Silva Sánchez, MJ/ 
como hubiera sido lo normal, sino que creó una norma nueva ad hoc para ello, decisión que ha sido muy criticada pero que presenta razones que la justifican ${ }^{19}$.

Por un lado, todos los supuestos enumerados en el art. 346 LSC como causas legales de separación tienen el común denominador de ser modificaciones de mayor envergadura de los estatutos sociales, las cuales hacen inexigible para el socio la permanencia en la sociedad. En efecto, el fundamento de estas causas legales es que no se puede obligar a ningún socio a permanecer en una sociedad con una organización societaria trascendentalmente distinta de la originaria, razón por la que se debe conceder una vía de escape. Por su parte, la causa legal reconocida en el art. 348 bis LSC no surge de ninguna modificación de los pactos sociales por los cuales los socios se rigen sino de una conducta abusiva perpetrada por la mayoría social y canalizada a través de un acuerdo de Junta General destinando los beneficios de los ejercicios sociales a partidas distintas de su reparto en forma de dividendos. Es decir, en este caso, el fundamento del supuesto previsto en este precepto de nueva planta es el abuso de derecho y la opresión que la mayoría ejerce sobre la minoría del capital social y que se materializa en la falta de retribución a los mismos como manifestación del ánimo de lucro, debiendo el ordenamiento jurídico proporcionar una salida para evitar que se sigan instrumentando estas conductas opresivas ${ }^{20}$.

Por otro lado, las causas legales y estatutarias de separación asumen una perspectiva ex ante de este derecho en el sentido de que la Ley o los estatutos prevén qué supuestos facultan al socio para ejercitarlo y salir de la sociedad antes de que esos supuestos tengan lugar. El art. 348 bis, por el contrario, presenta una configuración ex post, pues sólo puede ser calificado si concurre o no el supuesto de separación de forma sobrevenida, es decir, si se dan los requisitos previstos en la norma al caso concreto de no distribución de dividendos. En efecto, no toda negativa al reparto de los beneficios como dividendos da lugar al derecho de separación ex art. 348 bis sino únicamente aquellos casos en los que se dan los requisitos previstos en la norma.

Por último, las causas del art. 346 LSC se generan ante la adopción de un acuerdo por

Sambeat Sastre, JM. 2012. Análisis y crítica del artículo 348 bis de la Ley de Sociedades de Capital. Diario La Ley. 7844:3, también considera el supuesto del art. 348 bis LSC incluido entre las causas legales de separación y sometido a la disciplina del art. 346 LSC. En el mismo sentido, Vela Torres, PJ. 2013. El derecho de separación del socio en las sociedades de capital: una reforma incompleta y parcialmente fallida. Derecho de los Negocios. 268:55.

19 González Castilla, F. pp. 315-316.

20 González Castilla, F. p. 316: “(...) mientras que el art. 348 bis permite la valoración del ejercicio correcto o abusivo del derecho (...), el resto de causas legales dificilmente pueden ser ejercitadas abusivamente, al plantearse como el contrapeso necesario al poder mayoritario de modificación de determinados aspectos esenciales del contrato social'; Iraculis Arregui, N. 2012. La separación del socio sin necesidad de justificación: por no reparto de dividendos o por la propia voluntad del socio. Revista de Derecho de Sociedades. 38:234: "En virtud de este precepto, la falta de distribución de dividendos al socio es una causa de separación, ya que este comportamiento hace ilusorio el primordial propósito del socio al ingresar en la sociedad, esto es, obtener unos beneficios de su inversión, esencialmente a través de los dividendos. Indudablemente, desde que entra a formar parte de la sociedad el socio mantiene una intima relación con el lucro social, siendo el destino natural de los beneficios obtenidos por la sociedad su reparto entre los socios". 
mayoría de la Junta en el sentido de modificar los estatutos sociales mientras que el supuesto de hecho del art. 348 bis contempla la no adopción de un acuerdo por la Junta para distribuir los beneficios. Si bien es cierto que en ambos casos habrá manifestación de la voluntad social por mayoría, sea para alterar los estatutos sociales (art. 346 LSC) o sea para destinar el beneficio a un fin distinto del reparto de dividendos (art. 348 bis LSC), la Ley pone el acento en el "no acordar la distribución de dividendos", es decir, que lo que legitima al socio para ejercitar el derecho de separación es el acuerdo de Junta frustrado frente al cual el socio ha votado a favor.

En conclusión, el supuesto de hecho previsto en el art. 348 bis LSC constituye una nueva causa legal de separación y debe situarse al mismo nivel que las previstas en el art. 346 LSC y, por referencia de este texto, en los preceptos de la LME, si bien se ubica en una norma distinta por la diferente naturaleza y fundamento del supuesto que hace surgir la facultad de la separación.

\section{NATURALEZA DEL DERECHO RECONOCIDO EN EL ART. 348 BIS LSC}

Debemos poner de manifiesto que, a nuestro juicio, el art. 348 bis LSC no concede, en ningún caso, un derecho a un dividendo mínimo. Si bien la dicción literal de la norma es la que es, la interpretación debe ir más allá del mero sentido de las palabras ya que se debe tener en cuenta el ordenamiento jurídico dentro del cual se encuadra la norma. La LSC contempla exclusivamente un derecho abstracto del socio a participar en el reparto de las ganancias sociales, derecho que sólo se puede concretar a través del correspondiente acuerdo de la Junta General, único órgano competente para decidir sobre la distribución de un dividendo en nuestro Derecho de Sociedades. Desde esta perspectiva, podemos decir que lo que viene a conceder el art. 348 bis es un derecho al socio disidente, no viniendo en ningún caso a imponer una obligación a la sociedad ${ }^{21}$.

Desde un punto de vista formal, el derecho al beneficio sigue siendo un derecho abstracto pues el precepto en cuestión no ha venido a suprimir la competencia de la Junta General para decidir sobre la aplicación del resultado, aunque desde luego, se ha reforzado el derecho del socio a participar en las ganancias sociales. Cuando se celebre la Junta General que vaya a decidir sobre la aplicación del resultado del ejercicio, aquélla tendrá varias opciones disponibles: (i) distribuir como dividendo, al menos, un tercio de los beneficios propios de la explotación; (ii) distribuir una cantidad menor a ese tercio del beneficio; o (iii) no distribuir nada. Se observa así cómo la Junta sigue siendo libre para ejercitar su competencia, si bien, frente a la actuación de este órgano, el socio afectado podrá ejercitar el derecho de separación. Como hemos defendido, el socio que haya votado a favor de la

21 González Castilla, F. p. 324. En contra se manifiestan, entre otros, Brenes Cortés, J. 2011. El derecho de separación, principales novedades tras las últimas modificaciones operadas en el derecho de sociedades. Revista de Derecho de Sociedades. 37:31-32; García Sanz, A. p. 63. 
distribución de dividendos es titular de un derecho, siendo por tanto libre para ejercitarlo o no según su criterio. Por su parte, la Junta es también libre para tomar la decisión que desee en esta materia pero debe tener presente que su actuación podrá desencadenar la separación de uno o varios socios, aspecto que deberá valorar si quiere evitar las consecuencias que pueden surgir de tal proceder.

En definitiva, lo que el art. 348 bis LSC viene a hacer es limitar la discrecionalidad de la Junta a la hora de decidir la aplicación del resultado del ejercicio. Es cierto que el reconocimiento de un derecho de separación ante la falta de distribución de dividendos puede actuar como una medida de presión por las consecuencias patrimoniales que puede ocasionar pero la eficacia de la norma es precisamente esa: que la Junta, y sobre todo los socios mayoritarios, reflexionen acerca del resultado que tendría el no repartir dividendos pudiendo hacerlo por estar la sociedad perfectamente saneada y una vez atendidas las reservas legales y estatutarias, siendo este hecho constitutivo de una actuación abusiva que tendría como único objetivo oprimir a la minoría. El fin de esta norma, por tanto, no es conceder un derecho a un dividendo mínimo sino otorgar al socio un mecanismo de defensa ante el abuso de derecho que genera el no reparto de los beneficios sin una causa legítima, es decir, la expropiación del beneficio que tiene lugar y que no puede ser tolerada ni amparada por nuestro ordenamiento jurídico ${ }^{22}$.

La norma contemplada se presenta así como una medida que refuerza la posición del socio minoritario y que le permite enfrentarse a la tiranía desplegada por la mayoría a través

22 Iraculis Arregui, N. p. 235: "El derecho a participar en el reparto de las ganancias sociales que configura la Ley no es un derecho al reparto anual de los beneficios, participando con esa regularidad en los mismos, en su totalidad o en parte, a través de los dividendos, por lo que no cabe admitir como supuesto de hecho del derecho de separación la exclusión del reparto anual, en nuestro ordenamiento, a partir del quinto ejercicio desde que la sociedad queda constituida. La sociedad es libre de decidir distribuir, en su totalidad o en parte, o retener y autofinanciarse, siempre que tal decisión no sea abusiva. Que sea natural repartir dividendos anualmente, en virtud del carácter lucrativo que suele justificar la constitución de sociedades de capital, es algo muy distinto a considerar que dicho reparto resulte legalmente obligatorio. La validez del acuerdo social contrario a la distribución de dividendos tiene, entre otros límites, el límite fundado en el ejercicio abusivo por la mayoría de su facultad de decisión en relación con la aplicación de los beneficios del ejercicio. El acuerdo abusivo de no distribución de dividendos es impugnable con base en el instituto jurídico consagrado en el artículo 7.2 del Código Civil, al establecer que "la Ley no ampara el abuso de derecho o el ejercicio antisocial del mismo", y podría constituir un supuesto legal que otorga el derecho de separación, ya que estaríamos ante un comportamiento que hace opresiva la relación y por tanto inexigible para el socio permanecer en la sociedad. Por el contrario, no debería admitirse la separación en caso de simple falta de distribución de dividendos, como si rigiese una obligación de reparto a los socios de los beneficios conseguidos en el ejercicio corriente. En nuestro Derecho de sociedades no rige una obligación de total o parcial reparto y, además, el derecho de separación cumple una función de tutela del socio minoritario, por lo que resulta muy discutible apoyar una causa legal de separación en la defensa de un interés o expectativa, por muy legítima que sea, en atención a que una medida tan grave como el derecho de separación se ha de reservar para supuestos realmente trascendentes en los que pueda afirmarse que es inexigible al socio permanecer en la sociedad. Y aquí, es donde entra en juego el abuso de mayoría, como un criterio que objetiva la inexigibilidad de la permanencia en la sociedad. una aplicación concreta sobre cómo la mayoría abusa del socio minoritario la encontramos en el reiterado e injustificado no reparto de dividendos entre los socios, por lo que este supuesto sí podría encontrar cabida en la Ley como causa legal de separación, en sustitución del ya vigente caso de privación del dividendo". En contra, González Castilla, F. p. 324. Por nuestra parte, el derecho de separación del art. 348 bis LSC pretende "parchear" una manifestación de un problema mayor: el abuso de derecho realizado por los socios mayoritarios frente a los minoritarios. Si bien estamos de acuerdo con que lo que debería configurarse como causa legal de separación es el abuso de derecho en sí, no creemos que este primer paso dado por el legislador sea injustificado y discutible pues el no reparto de dividendos es una de las manifestaciones más claras de ese abuso de derecho subyacente y tiene la suficiente entidad como para ser merecedora de la protección dispensada por el derecho de separación. 
del ejercicio del derecho de separación, el cual deberá ser utilizado conforme a los postulados de la buena fe para que no se produzca la inversión de la situación que el art. 348 bis pretende eliminar, esto es, que no se produzca bajo ningún concepto el paso desde el abuso de la mayoría al abuso de la minoría ${ }^{23}$. A nuestro juicio, el ejercicio bajo el paraguas de la buena fe del derecho de separación por falta de distribución de dividendos conlleva también la conciencia de la importante cantidad del beneficio que se distribuirá como dividendos y que podría poner a la sociedad de capital no cotizada contra las cuerdas al debilitarse su solvencia y su solidez financiera, pudiendo incluso entrar en concurso de acreedores ${ }^{24}$.

\section{CONDICIONES PARA EL RECONOCIMIENTO DEL DERECHO DE SEPARACIÓN}

\section{Transcurso de cinco ejercicios desde la inscripción en el Registro Mercantil}

Lo primero que viene a establecer el art. 348 bis LSC es un límite temporal al precisar que el derecho de separación por falta de pago de dividendos sólo podrá ser ejercitado por los socios a partir del quinto ejercicio a contar desde la inscripción en el Registro Mercantil de la sociedad. Este límite no hace referencia a que necesariamente hayan pasado cinco ejercicios sin que la sociedad haya procedido a repartir dividendos sino a que la sociedad lleve cinco ejercicios constituida e inscrita ${ }^{25}$.

En este sentido, se supone que en el cómputo de los cinco ejercicios deberá incluirse necesariamente el que se inicie desde la inscripción, el cual podrá ser inferior a 12 meses y tener, por tanto, un cierre abreviado. Además, la expresión "a partir" parece indicar que el quinto ejercicio queda incluido en el cálculo y, por extensión, sus resultados, los cuales serán aprobados por la Junta del ejercicio siguiente, esto es, del sexto ejercicio ${ }^{26}$. Así, y a pesar de la absoluta falta de claridad de este precepto, entendemos que el derecho de separación surgiría a partir del quinto ejercicio incluido, por lo que podrá ejercitarse tras la Junta ordinaria siempre que se hubieran obtenido beneficios en el ejercicio anterior, ya que es durante el quinto

\footnotetext{
23 García Sanz, A. p. 64; González Castilla, F. p. 324.

24 Pulgar Ezquerra, J. 2017. pp. 157 y ss.

25 Este hecho elimina el carácter antiopresivo que el legislador pretendía dar a la norma, en opinión de Silva Sánchez, MJ/ Sambeat Sastre, JM. p. 3; González Castilla, F. p. 331, establece que lo único que hace el art. 348 bis es establecer un plazo de vida, una fecha ad quem a partir de la cual puede aparecer el derecho de separación.

26 Esta interpretación se ve avalada por la Sentencia del Juzgado Mercantil número 9 de Barcelona de 25 de septiembre de 2013 y en este mismo sentido se manifiesta González Castilla, F. p. 331. No queda tan claro para Silván Rodríguez, F/ Pérez Hernando, I. p. 4: "Sin embargo, la expresión "a partir del quinto ejercicio a contar desde la inscripción en el Registro Mercantil" suscita numerosas dudas. Si se considera que "a partir" incluye dicho quinto ejercicio, se podría colegir bien que se refiere a la junta ordinaria del quinto ejercicio (en la que se decide sobre la aplicación del resultado del cuarto), o bien a los resultados del quinto ejercicio (cuya decisión de distribución se adoptará en el sexto ejercicio). Por el contrario, si consideramos "a partir" como una expresión excluyente del quinto ejercicio, tendríamos que estar a los beneficios del sexto ejercicio, cuya decisión se tomaría en la junta del séptimo".
} 
ejercicio cuando se decidirá la aplicación del resultado obtenido durante el cuarto ejercicio.

Por otra parte, este precepto entró en vigor el 2 de octubre de 2011, por lo que no resulta claro si se debe aplicar la norma respecto de los beneficios generados durante el ejercicio 2011 o en el 2012, ya que para el primer caso habría una aplicación retroactiva de la norma y todo ello en un contexto en el que no se cuenta con una disposición transitoria que regule la aplicación de este precepto para los casos de las sociedades ya existentes. Además, ¿qué ocurre para los casos de modificaciones estructurales? Parece no haber dudas para el caso de la transformación en tanto en cuanto en virtud de esta modificación estructural, la sociedad adopta un tipo social distinto pero conserva su personalidad jurídica, de tal suerte que el cómputo debería producirse desde la inscripción del tipo social primigenio ${ }^{27}$. Sin embargo, este extremo puede causar graves controversias para los casos de fusiones y escisiones. En el caso de la fusión, podemos entender que el cómputo se realizaría a partir del día de la inscripción de la constitución de la sociedad absorbente, si fuera fusión por absorción, o de inscripción de la fusión, en caso de hacerse mediante la creación de una nueva sociedad, y ello sobre la base de que acontece una disolución sin liquidación que responde a la necesidad de asegurar la continuación de las relaciones jurídicas preexistentes que se transmiten, sin sufrir modificación a su paso a la sociedad absorbente o a la nueva sociedad ${ }^{28}$. Semejante problemática conceptual de la personalidad jurídica tendríamos para el caso de que aconteciese una escisión o una segregación a una sociedad preexistente.

Sin duda, para evitar las dudas interpretativas puestas de manifiesto, hubiera sido más acertado referir el límite temporal al número de ejercicios sin distribución de dividendos, dado que así se conectaría la norma con una finalidad anti abusiva y de protección a la minoría al mismo tiempo que se concretaría la jurisprudencia existente sobre el momento a partir del cual se entiende que el no reparto de dividendos es abusivo ${ }^{29}$.

27 Sin embargo, se apunta en Silva Sánchez, MJ/Sambeat Sastre, JM. p. 4, el caso de una cooperativa que se transforma en sociedad de capital, de tal forma que si se considera que la inscripción de la transformación es constitutiva, lo lógico sería computar los cinco ejercicios desde su inscripción.

28 Consideraciones vistas en Silván Rodríguez, F/Pérez Hernando, I. p. 5, donde se añade, además: “(...) mediante la fusión la sociedad absorbente (o de nueva creación) recibe e incorpora en su propia estructura interna la totalidad de las relaciones que giraban alrededor de la sociedad absorbida. Tal teoría podría servir de base para el minoritario cuya sociedad absorbida llevaba más de cinco años inscrita, y que ahora sin contar sin su consentimiento ha derivado en una absorbente de reciente inscripción, aunque resulta evidente que al carecer el argumento de reflejo positivo tendrá que ser fruto, en su caso, de construcción jurisprudencial".

29 El abuso de derecho se caracteriza por la legalidad objetiva del derecho o facultad que se ejercita, la ilegitimidad subjetiva del fin perseguido, que reside en la intención de causar daño a otro y el daño a un interés no directamente protegido por una específica prerrogativa jurídica. Para el caso concreto del no reparto de dividendos observamos cómo existe una norma que permite la retención de dividendos (art. 273 LSC), cómo esa actuación causa daño a los socios minoritarios que no ven incrementado su patrimonio individual con cantidades que podrían repartirse como dividendos y cómo el daño que se les causa es injustificado en tanto en cuanto la retención de beneficios no pretende fortalecer el patrimonio de la sociedad sino dañar a los socios minoritarios (vid. García Sanz, A. p. 59). Podemos traer a colación los casos de la Sentencia del Tribunal Supremo de 26 de mayo de 2005, que consideró abusivo privar al socio minoritario, sin causa acreditada alguna, de su derecho a participar en 


\section{No acordar la distribución como dividendo de, al menos, un tercio de los beneficios}

\section{legalmente repartibles derivados de la explotación del objeto social}

Bajo esta condición lo que la norma establece es un límite cuantitativo para reconocer el derecho de separación al socio, esto es, que la Junta no acuerde la distribución como dividendo de, al menos, un tercio de los beneficios propios de la explotación del objeto social que sean legalmente repartibles.

Por lo que respecta a la cantidad en sentido estricto, "al menos, un tercio", se ha criticado lo elevado de la cifra desde un punto de vista financiero, apuntándose además que, para los casos de entidades financieras no cotizadas, ese reparto puede ser contrario a los compromisos de Basilea III ${ }^{30}$. Así, que ese tercio establecido de forma rígida por el legislador sea una cantidad anual fija no parece justificado dado que un año la sociedad podría repartir una cantidad inferior a un tercio y al año siguiente una cuantía superior pero siempre con periodicidad anual. Por otro lado, es interesante reflexionar acerca de la duda consistente en que si siempre que se proceda a repartir un tercio de los beneficios de explotación queda excluida la posibilidad de que exista abuso de mayoría. En efecto, una sociedad que proceda a repartir cada año el tercio referido en el art. 348 bis LSC como dividendos y, al mismo tiempo, destine los dos tercios restantes o una cantidad similar a constituir reservas voluntarias injustificadas, sí que estaría, a nuestro juicio, cometiendo una actuación abusiva en la medida en que el socio estaría recibiendo un dividendo de una cuantía inferior a la posible al contar con reservas más que suficientes. En este caso, ¿podría el socio separarse por esta causa? En principio, tal y como está redactada la norma, no cabría la separación, debiendo seguir el socio

\footnotetext{
las ganancias sociales; la Sentencia de la Audiencia Provincial de Barcelona (Sección 15a) de 21 de enero de 2011 y la Sentencia de la Audiencia Provincial de Baleares (Sección 5a) de 22 de diciembre de 2010, en las que se han declarado abusivas la retención sistemática de dividendos cuando existen reservas voluntarias suficientes que justifican que la empresa se encuentra saneada financieramente En el mismo sentido se manifiestan las Sentencias de la Audiencia Provincial de Murcia (Sección $4^{\mathrm{a}}$ ) de 28 de noviembre de 2008 y de 27 de febrero de 2009 y la Sentencia de la Audiencia Provincial de Madrid (Sección 19a) de 7 de octubre de 2005, la cual declara que congelar ilimitadamente el reparto de los beneficios supone un daño grave para los intereses de la minoría con infracción del art. 7.2 del Código Civil, siendo el reparto de dividendos en una sociedad capitalista esencial por su propia configuración legal. En contra, la Sentencia de la Audiencia Provincial de Barcelona de 25 de julio de 1994 no apreció abuso de la mayoría en una sociedad que aplicó el beneficio a reservas voluntarias cuando la sociedad contaba con reservas más que suficientes. De la misma manera, la Sentencia de la Audiencia Provincial de León (Sección $2^{\mathrm{a}}$ ) de 6 de junio de 2003 no consideró abusivo el acuerdo en el que se decidía imputar la totalidad de los resultados obtenidos a reservas voluntarias. La Sentencia de la Audiencia Provincial de Valencia (Sección 9a) de 13 de octubre de 2008 entendió que la retención no era abusiva al estar justificada por razones económicas.
}

30 Brenes Cortés, J.2011. pp. 32-33: “Entendemos que la cuantía es ciertamente considerable, y que dicho reparto constituye una importante descapitalización de fondos propios de la sociedad, circunstancia que puede perjudicar los intereses de los acreedores. Por ello, no alcanzamos a comprender cuál es la razón por la que el legislador ha establecido una cifra de reparto tan alta. A esto hay que unir la propia desinversión que el ejercicio del derecho de separación implica"; Ibáñez García, I. 2012. La nueva regulación del derecho al dividendo en las sociedades de capital (no cotizadas). Derecho de los Negocios. 263-264:24: "De una parte, es inadecuada por excesivamente rígida, dado que los límites temporales (5 años) y proporcionales (mínimo de un tercio) impuestos por el legislador como máximos a la política de no reparto de dividendos (o como mínimos obligatorios en su reparto) son arbitrarios e inflexibles. (...) Especialmente en tiempos de crisis, en que el refuerzo de la solvencia de las sociedades es particularmente sensible, establecer una norma que obliga a las sociedades a repartir un tercio de sus resultados o enfrentarse a la separación forzosa de algunos de sus socios (potencialmente, cerca de la mitad) con la consiguiente reducción de sus reservas o de su capital, es particularmente contraproducente"; González Castilla, F. p. 333, nota 50. 
oprimido en esa sociedad a pesar de distribuir todos los años un tercio de sus beneficios ${ }^{31}$.

Por otro lado, el límite cuantitativo que estamos comentando se refiere a "los beneficios propios de la explotación del objeto social (...) que sean legalmente repartibles". En este sentido, el beneficio de la explotación no tiene por qué coincidir con el beneficio repartible ${ }^{32}$. Con esta expresión, procedente del art. 128.1 LSC, la norma se refiere a las ganancias que procedan exclusivamente de la actividad ordinaria de la sociedad, dejando a un lado los beneficios extraordinarios o atípicos, y ello aunque las normas contables no permitan distinguir, en las partidas del balance, los resultados debidos a la explotación del negocio de otros extraordinarios o distintos de esa explotación, dificultándose así su cálculo ${ }^{33}$.

Como se observa, el art. 348 bis LSC se refiere al concepto de beneficios legalmente repartibles. En este sentido, el reparto de dividendos se hace sobre la base de los beneficios netos de la sociedad, es decir, una vez deducidos los impuestos correspondientes y excluidas, en todo caso, las reservas ${ }^{34}$. No obstante, la norma hace referencia a dos conceptos que claramente chocan entre sí. Por una parte, se refiere a los beneficios propios de la explotación del objeto social, que son los resultados sin considerar los estados financieros y, en todo caso, antes de aplicar el impuesto sobre sociedades y, por otra, establece los beneficios legalmente repartibles, es decir, beneficios netos, lo que nos lleva a dos resultados completamente diferentes arrojando los beneficios de explotación una cifra de reparto todavía mayor que los legalmente repartibles. De nuevo, dudas y quebraderos de cabeza en la aplicación del art. 348 bis LSC, que, además de

31 González Castilla, F. p. 334. Estas dudas se han manifestado obiter dicta en la Sentencia del Tribunal Supremo de 7 de diciembre de 2011. El TS, tras reiterar que es constitutivo de abuso de derecho el privar al socio de su derecho a participar en el reparto de las ganancias sociales sin una causa justificada, señala que esta solución podría ser cuestionada bajo el régimen del art. 348 bis al establecer unos límites precisos. Se concluye así que, pese a no poder aplicarse la norma por razones temporales, no puede proyectarse sobre el que contrató con la sociedad una retribución vinculada al reparto de beneficios en la medida en que, en otro caso, dejaría al arbitrio de la contraparte la eficacia de lo pactado, siendo esto contrario a lo estipulado en el art. 1256 CC. Véase igualmente Vela Torres, PJ. p. 58.

32 Garrigues, J/Uría, R. p. 398: “(...) el beneficio en sentido jurídico mercantil no ha de coincidir necesariamente con el beneficio de la explotación. Puede un año haber beneficio en la explotación y no haber beneficio repartible; $y$, al contrario, puede haber beneficio repartible sin que la explotación en aquel año haya producido beneficio (...). El beneficio en la sociedad anónima es un beneficio del patrimonio más que un beneficio de la explotación, aunque ambos aspectos estén intimamente ligados, ya que todo beneficio de explotación se traduce siempre en un aumento patrimonial que llegará a constituir beneficio en sentido jurídico cuando eleve el activo por encima del nivel del pasivo, entendiendo por este tanto el exigible como el no exigible (indisponible)".

33 García Vicente, JR. 2011. Artículo 128. Reglas de liquidación del usufructo. In Rojo A/Beltrán, E. Comentarios a la Ley de Sociedades de Capital. Cizur Menor. p. 1027. Además, algunos autores han acudido a la contabilidad y han precisado que los resultados de la explotación son aquéllos antes de aplicar los resultados financieros y el impuesto sobre los beneficios societarios (vid. Silván Rodríguez, F/Pérez Hernando, I. 2012. Derecho de separación y dividendos: El controvertido artículo 348 bis LSC. Diario La Ley. 7813:5). Asimismo, Silva Sánchez, MJ/Sambeat Sastre, JM. p. 4, señala: "Recordemos que con la reforma contable se eliminó la distinción entre resultados ordinarios y extraordinarios, por lo que la locución que utiliza el art. 348 bis LSC puede dar lugar a problemas de interpretación".

34 Véase la Sentencia del Juzgado de lo Mercantil número 9 de Barcelona de 1 de marzo de 2018: "Que los beneficios sean legalmente repartibles. Es decir, una vez deducidos los impuestos correspondientes y excluidas, en todo caso, las reservas legales y estatutarias. Sobre este particular, cabe citar la sentencia dictada por este mismo juzgado en fecha 25/9/2013 según la cual: "Se podrán no repartir beneficios cuando se justifique en una limitación legal, como por ejemplo, en la necesidad de compensar pérdidas o de dotar reservas legales o estatutarias. El reparto de dividendos debe producirse en el momento en que la empresa ha hecho frente a todos sus gastos financieros y ha satisfecho los impuestos "',. 
las dudas anteriormente descritas, no dice nada acerca de la posibilidad de acordar dividendos en especie, por ejemplo ${ }^{35}$. Sin embargo, creemos que la expresión "los beneficios propios de la explotación del objeto social (...) que sean legalmente repartibles" hace referencia a que no se computarán los ingresos que no provengan de la actividad social pero no a que la base del cálculo no deban ser los resultados netos, es decir, una vez descontados los impuestos y excluidas las reservas ${ }^{36}$. En cualquier caso, la redacción es desafortunada por los problemas de interpretación que suscita y la alta litigiosidad que generará el precepto.

Así, dados los problemas interpretativos que la dicción literal de la norma puede generar, sería conveniente la introducción de una cláusula estatutaria en la que, sin perjudicar el derecho concedido, se intentase determinar con mayor precisión el concepto de beneficios propios de la explotación del objeto social para evitar así el déficit de seguridad jurídica ${ }^{37}$.

\section{Voto favorable a la distribución de beneficios por parte del socio}

El art. 348 bis LSC establece claramente que el legitimado para ejercitar el derecho de separación es "el socio que hubiera votado a favor de la distribución de los beneficios sociales". En este sentido, la norma parte de un comportamiento activo por parte del socio en el sentido de votar a favor pero, a nuestro entender, parece evidente que el socio también podrá hacer uso de este derecho en caso de que haya votado en contra de la aplicación del resultado decidido mayoritariamente por la Junta, sin necesidad de que exista una votación específica para decidir sobre el pago de dividendos ${ }^{38}$. Lo importante, en cualquiera de los casos, es que quede clara la postura del socio a favor de la distribución de dividendos, sea emitiendo un voto favorable al reparto o uno contrario a la aplicación del resultado a partidas distintas del pago de dividendos, siendo recomendable, para este último caso, que el socio exigiera que constase en el acta de la Junta su disconformidad con el destino de los beneficios aprobados y su intención favorable al reparto de dividendos a los efectos de ejercitar el derecho que le asiste ex art. 348 bis LSC. Sin embargo, la norma es clara en este punto por lo que habrá que esperar a ver cómo la aplican los órganos jurisdiccionales ${ }^{39}$.

35 Silva Sánchez, MJ/Sambeat Sastre, JM. p. 4, donde los autores, después de decir que la expresión "legalmente repartibles" genera confusión, lanzan las siguientes cuestiones: ¿Se refiere al beneficio del ejercicio o al beneficio repartible? ¿Incluye las reservas disponibles? ¿Y los resultados de ejercicios anteriores?

36 González Castilla, F. p. 335. Así, la Sentencia del Juzgado de lo Mercantil número 9 de Barcelona de 25 de septiembre de 2013 establece: "Entiendo, por tanto, que la indicada expresión se refiere a la actividad ordinaria de la sociedad y que excluye, entre otros supuestos, los beneficios extraordinarios y las plusvalias susceptibles de ser reflejadas en la contabilidad".

37 Silván Rodríguez, F/Pérez Hernando, I. p. 5.

38 En este mismo sentido, González Castilla, F. p. 335.

39 Silva Sánchez, MJ/Sambeat Sastre, JM. p. 4: "Como requisito para el ejercicio del derecho de separación por falta de distribución de dividendos, el precepto obliga a los minoritarios a votar "a favor de la distribución de beneficios". Sin embargo, la interpretación y aplicación de este requisito se topa con una dificultad práctica: es frecuente que, en el contexto de aplicación de este precepto, el punto de la propuesta de acuerdos para la junta general ordinaria relativo a la aplicación del resultado no incluya distribución de dividendo alguna, sino que propondrá su íntegra aplicación a reservas, por lo que los accionistas minoritarios no podrán votar a favor de ninguna propuesta de distribución de beneficios; solo podrán votar 
Mas ¿qué sucedería si no hay cuentas anuales aprobadas porque el órgano de administración no ha procedido a convocar la Junta General Ordinaria? En este caso, lo primero que tiene que hacer el socio es instar judicialmente la convocatoria de la Junta tal y como permite el art. 169.1 LSC para que, tras la aprobación de las cuentas anuales, se pueda pasar a votar la aplicación del resultado obtenido en el ejercicio anterior.

Otro problema relacionado con el voto es el de qué ocurre con los socios sin voto en tanto en cuanto el art. 348 bis LSC no se pronuncia sobre este extremo como sí hace el art. $346 \mathrm{LSC}^{40}$. En efecto, el art. 346 LSC concede el derecho de separación a los socios que no hayan votado a favor del correspondiente acuerdo, incluidos los socios sin voto. En la medida en que tanto lo recogido en este precepto como lo contenido en el art. 348 bis LSC constituye causa legal de separación, podemos interpretar, y sería lógico hacerlo, que los socios sin voto también podrán ejercitar el derecho de separación por falta de reparto de dividendos, si bien hubiera sido deseable una mención expresa en tal sentido ${ }^{41}$. Además, en apoyo de nuestra interpretación, podemos traer a colación lo previsto en el art. 99.1 LSC, ya que, además de tener derecho al dividendo mínimo establecido estatutariamente, los socios sin voto tendrán derecho al mismo dividendo que corresponda a las participaciones sociales o a las acciones ordinarias, lo que muestra que podrán separarse si no se les reparte, al menos, un tercio de los beneficios de explotación ex art. 348 bis LSC, tal y como pueden hacer los socios ordinarios.

Finalmente, para los casos en los que la mayoría lleve a cabo actuaciones destinadas a reducir o eliminar el beneficio del ejercicio con carácter previo a la aprobación de las cuentas anuales y a la decisión acerca de la aplicación del resultado del ejercicio, el socio podrá impugnar primeramente el acuerdo de Junta que apruebe esas cuentas para, posteriormente, ejercitar el derecho de separación ${ }^{42}$.

en contra de su integra aplicación a dotación de reservas. Ello obligará a interpretar este voto en contra como equivalente a un voto a favor de la distribución de beneficios sociales, lo cual supone añadir una dificultad más a un contexto que suele ser conflictivo, por lo que es muy probable que esta interpretación deba realizarse en sede judicial. En cualquier caso, debe entenderse que el ejercicio de este derecho requiere un previo voto en contra de la aplicación del beneficio del ejercicio a dotación de reservas que conste en acta"; Silván Rodríguez, F/Pérez Hernando, I. p. 4: "Puede darse el caso de que los administradores no incluyan la distribución como orden del día, sino tan solo su destino a reservas. En tal caso el minoritario votaría en contra, por lo que puede que el juzgador equiparase el voto contrario al voto favorable al que se refiere la Ley siempre y cuando se dejase constancia en el acta de la voluntad del disidente a favor del reparto"; García Sanz, A. pp. 66-67; Vela Torres, PJ. pp. 57-58.

40 Silva Sánchez, MJ/Sambeat Sastre, JM. p. 4.

41 No mantienen esta misma interpretación García Sanz, A. p. 67, quien considera que los titulares de acciones o participaciones sin voto no están legitimados para ejercitar este derecho salvo que adquieran el derecho de voto en determinadas circunstancias (arts. 99.3 y 100.2 LSC). En estas situaciones, los titulares sin voto podrán estar legitimados para ejercer el derecho de separación si votan a favor del reparto de dividendos en el respeto a las condiciones preestablecidas en el art. 348 bis LSC; Rodas Paredes, P. p. 103, mantiene que la esencia de las acciones o participaciones sin derecho de voto es la garantía de la protección de los derechos económicos de sus titulares, razón por la que estos socios no podrían separarse alegando la causa del art. 348 bis LSC al estar ya garantizados sus derechos económicos.

42 González Castilla, F. p. 336. Por ejemplo, es interesante la Sentencia del Tribunal Supremo de 5 de octubre de 2011 en un supuesto donde los beneficios recogidos en las cuentas de la sociedad eran muy inferiores a los reales. En este sentido, recoge la sentencia: “(...) mediante acuerdos adoptados por el grupo familiar mayoritario de accionistas, viene vulnerando 


\section{LA SEPARACIÓN POR JUSTA COMO RETO DEL DERECHO MERCANTIL}

Una de las bondades que ha tenido el art. 348 bis LSC, y que conviene destacar en nuestra opinión, es haber puesto sobre el tapete la necesidad de que se articule un sistema de protección a los socios minoritarios frente a cualquier situación que genere opresión, no siendo este precepto aplicable únicamente al caso de que no se distribuya como dividendo, al menos, un tercio de los beneficios de la actividad ordinaria, sino que aquel constituye la expresión de un principio general de protección del socio minoritario frente a los incumplimientos esenciales del contrato de sociedad ${ }^{43}$. Por esta razón, ciertos sectores de la doctrina vienen reclamando el establecimiento del derecho de separación por justa causa como vía de tutela de los socios ante cualquier tipo de comportamiento abusivo ${ }^{44}$.

A diferencia de otros sistemas jurídicos continentales, como el suizo o el alemán, nuestro ordenamiento no contempla aun la posibilidad de los "justos motivos" como causa de separación para las sociedades de capital $^{45}$. El sistema elegido por la LSC consiste en dar unos supuestos tasados de lo que se considera incumplimiento esencial del contrato social (causas legales), así como la posibilidad de que los socios configuren estatutariamente los motivos que pueden dar lugar al ejercicio del derecho de separación (causas estatutarias) ${ }^{46}$. Sin perjuicio de esta última posibilidad, los socios no pueden prever absolutamente todos los supuestos que pueden acontecer a futuro y que deben ser necesariamente asociados a la activación de este mecanismo de protección, razón por la que el sistema no puede ser eficiente. La ventaja que tendría el establecimiento de una cláusula general por justa causa sería precisamente evitar que supuestos importantes quedasen fuera de la Ley y, por tanto, sin

\footnotetext{
sistemáticamente el derecho de información de los accionistas demandantes-recurridos en un punto que afecta de modo esencial a la cuentas e imagen fiel del patrimonio social. La consecuencia de este comportamiento global es que, al arrastrarse indefinidamente presuntas deudas sociales de ejercicio en ejercicio, los beneficios formalmente reflejados en las cuentas de la sociedad sean probablemente muy inferiores a los reales, repercutiendo así en el acuerdo de aplicación de resultado y, consecuentemente y de forma negativa, en el derecho de los demandantes-recurridos a participar en las ganancias sociales o derecho al dividendo. Como declaró la sentencia de esta Sala de 26 de mayo de 2005, si bien este derecho "no es un derecho absoluto de reparto de todos los beneficios, pues aparte de las reservas legales se pueden constituir otras de carácter voluntario", no cabe "privar al socio minoritario, sin causa acreditada alguna, de sus derechos a percibir los beneficios sociales obtenidos y proceder a su retención sistemática", pues semejante actuación se presenta como "abusiva, que no puede obtener el amparo de los tribunales"'.
}

43 Vázquez Lépinette, T. 2012. La separación por justa causa tras las recientes reformas legislativas. Revista de Derecho Mercantil. 283:184.

44 Vázquez Lépinette, T. p. 181: "La jurisprudencia considera que existe justa causa si existe un desacuerdo profundo y permanente que impide de hecho cualquier colaboración ulterior entre los socios. No es necesario que proceda de un comportamiento doloso, pero es necesario que sea imputable al socio frente al que se ejercita el derecho de compra forzosa".

45 El Anteproyecto de Ley de Código Mercantil español, aún en tramitación parlamentaria, reconoce en su art. 271-1 el derecho de separación por justa causa para toda clase de sociedades mercantiles.

46 La tipificación legal de las causas de separación resulta insuficiente y hasta incongruente. Así, véase las críticas sobre esta situación en Alfaro Águila-Real, J. 1996. Conflictos intrasocietarios (Los justos motivos como causa legal no escrita de exclusión y separación de un socio en la sociedad de responsabilidad limitada). Revista de Derecho Mercantil. 222:1133. Además, en Viera González, AJ. 2002. Las Sociedades de Capital Cerradas. Un problema de relaciones entre los tipos SA y SRL. Cizur Menor. pp. 67-68, se parte de la idea de que los supuestos previstos legalmente no cubren por sí solos el problema de la protección del socio minoritario. 
protección del ordenamiento, constituyendo esta aspiración, sin duda, unos de los retos que presenta hoy día el Derecho Mercanti1 ${ }^{47}$.

Sin embargo, si bien la separación por justos motivos no aparece regulada para las sociedades de capital, no podemos decir que nuestro Derecho de Sociedades desconozca esta posibilidad completamente, en tanto en cuanto la justa causa de separación está prevista en el art. 13 de la Ley de Sociedades Profesionales y art. 15 de la Ley de Agrupaciones de Interés Económico. Por ello, no siendo una novedad en nuestro sistema legal, no alcanzamos a comprender la razón por la que no se extiende este sistema a las sociedades de capital y, más aún, a las sociedades de capital cerradas. Se trataría de que los socios pudieran ampararse en la existencia de justos motivos para separarse de una sociedad de capital cerrada, siempre y cuando la relación societaria hubiera devenido intolerable y el conflicto intrasocietario existente no pudiera resolverse de ninguna otra forma ${ }^{48}$.

Así, por justa causa de separación podemos entender cualquier comportamiento o circunstancia concurrente que haga que la permanencia en la sociedad no pueda ser exigida a ningún socio y, además, que no exista ningún otro remedio para solucionar la situación a la que aquel se está enfrentando ${ }^{49}$. Este otro remedio consistiría en la posibilidad de transmitir la condición de socio, lo cual es relativamente sencillo en las sociedades abiertas pero no lo es tanto en las cerradas por la configuración que las mismas presentan. De esta forma, al no poder los socios vender libremente sus acciones o participaciones ni poder ejercitar la denuncia propia de las sociedades de personas, el único remedio que parece poder esgrimirse es el ejercicio de la separación. Si la circunstancia que hace que la permanencia en la sociedad de capital sea inexigible no aparece dentro del catálogo de las causas legales o estatutarias de separación, ¿qué solución tiene el socio? Claramente la regulación legal es insuficiente y los supuestos legales muy restrictivos ${ }^{50}$.

Además, el principio de denunciabilidad de las relaciones duraderas, esto es, la idea de que nadie puede quedar vinculado eternamente, quedaría vulnerado en el supuesto de hecho que estamos barajando, siendo por tanto este principio y la posibilidad de desengancharse

47 Martínez Sanz, F. p. 44.

48 Martí Miravalls, J. 2010. La ampliación del derecho de separación del socio en las sociedades de capital cerradas. In Hierro Anibarro, editor. Simplificar el Derecho de Sociedades. Madrid. p. 496.

49 Alfaro Águila-Real, J. 1996. pp. 1100, 1113-1114: “Constituyen justos motivos de separación, a nuestro juicio, dos conjuntos de circunstancias. En primer lugar, la adopción por la sociedad de medidas que modifiquen la situación jurídica y económica del socio en una forma que su aceptación no resulte exigible para el socio. En segundo lugar, y la existencia de un conflicto permanente y duradero entre mayoría y minoría cuyo origen se encuentre en el comportamiento antiestatutario o ilegal de la mayoría"; Fernández del Pozo, L. p. 280: "Suele entenderse que constituye justa causa cualesquiera incumplimientos graves de las obligaciones sociales aunque sean incumplimientos parciales o no reiterados y aunque tales incumplimientos no sean culpables o dolosos. No sólo eso: se entiende que, en general, procede reconocer justa causa para la separación en todas aquellas situaciones en que deba convenirse en la inexigibilidad de la permanencia del socio dentro de la sociedad'; Martínez Sanz, F. p. 34.

50 Alfaro Águila-Real, J. 1996. p. 1113. 
de una relación pensada como permanente cuando existen razones justas para ello (denuncia extraordinaria), uno de los argumentos esenciales para aceptar el derecho de separación por justa causa ${ }^{51}$. Por tanto, los principales argumentos a favor de la separación por justos motivos son la presencia del principio de denunciabilidad y la denuncia extraordinaria en nuestro sistema jurídico así como el reconocimiento de los justos motivos en los casos de las sociedades profesionales y las agrupaciones de interés económico.

Frente a los que apoyan la existencia de la justa causa de separación se alzan aquellos que sostienen que esta cláusula general no es posible sencillamente porque la Ley no lo prevé asi $^{52}$. Además existe el llamado prejuicio ideológico, consistente en que el legislador se ha dejado llevar excesivamente por el modelo de derecho de separación construido para el caso de la sociedad anónima abierta ${ }^{53}$. Se trata éste de un escenario en el que, al poder el socio liquidar su inversión inmediatamente mediante la venta de sus acciones, el derecho de separación adopta un carácter meramente residual y objetivo anudado a específicas modificaciones estatutarias. Por el contrario, en las sociedades cerradas el derecho de separación adopta un papel fundamental como mecanismo de defensa de los socios minoritarios en aquellos casos en los que tenga lugar una modificación sustancial de los elementos esenciales del contrato de sociedad, abarcando esta categoría tanto los supuestos de modificación estatutaria como los comportamientos que hacen opresiva la relación y por tanto inexigible para el socio permanecer en ella.

Un socio querrá abandonar la sociedad cuando tengan lugar conflictos o enfrentamientos entre socios, fundamentalmente entre mayoría y minoría, pudiendo esos conflictos venir por la vía de las modificaciones estatutarias o motivados por otras circunstancias no previstas en la Ley o en los estatutos. En estos casos, el socio sólo tiene abierta la vía de la impugnación judicial de los acuerdos, no pudiendo separarse en las situaciones graves que hacen que su permanencia en la sociedad sea a todas luces insoportable. Pero es que, además, habrá casos en los que concurriendo una de las modificaciones estatutarias previstas en el art. 346 LSC no pueda el socio ejercitar este derecho porque tal modificación no encaje en el supuesto de hecho previsto por la norma. Pensemos, por ejemplo, en una modificación de hecho del objeto social, extremo no previsto en el art. 346.1 a) LSC. Todos estos problemas, y otros muchos, se solucionarían mediante el reconocimiento del derecho de separación por justos motivos.

51 González Castilla, F. pp. 306-307; Alfaro Águila-Real, J. 1996. p. 1108-1115. En contra, Fernández del Pozo, L. p. 279 y ss.

52 Martínez Sanz, F. pp. 104-106, nota 124, donde el autor pone de manifiesto que si el legislador hubiera querido dejar la puerta abierta a la cláusula general de separación por justos motivos lo habría hecho expresamente. Además señala que ¿de qué serviría la enumeración de las causas legales si existiera esta cláusula general de separación con independencia de que el motivo se haya previsto o no en los estatutos? Por su parte, Alonso Ledesma, C. pp. 105-106, considera que en el sistema legal español no cabe establecer una cláusula estatutaria de separación por justos motivos pues no se acomodaría al art. 347 LSC.

53 Expresión utilizada en Alfaro Águila-Real, J. 1996. pp. 1130 y ss. 
A favor de la introducción de los justos motivos en nuestro Derecho de las sociedades de capital hemos de precisar que existen ciertos precedentes en nuestra jurisprudencia apoyando la justa causa de separación, además del reconocimiento legal que ya existe para las sociedades profesionales y las agrupaciones de interés económico. En concreto, nos estamos refiriendo a la Sentencia del Tribunal Supremo de 10 de febrero de 1997, en la que se consideró procedente la pretensión de separación voluntaria esgrimida por un socio en el que concurría justa causa, declarando que la inexistencia de un expreso reconocimiento de ese derecho en la Ley no constituía un obstáculo decisivo para su admisibilidad ${ }^{54}$.

Por tanto, con base en lo hasta ahora dicho, no parece forzado extraer la existencia de un principio de justa causa de separación no escrito, de tal forma que la falta de previsión legal y estatutaria no debería ser óbice para impedir al socio separarse de la sociedad cuando, sin tener posibilidad de resolver el conflicto existente a través de otro mecanismo de resolución, se produzca el acaecimiento de un hecho de una gravedad tal que resulte inexigible para el socio seguir vinculado a la sociedad. Además este principio de justa causa de separación será especialmente necesario en las sociedades cerradas, organismos en los que por su configuración particular el socio minoritario carece de la debida tutela a través de las causas legales de separación. Si bien el socio dispone de la posibilidad de añadir causas estatutarias de separación, las capacidades humanas de previsión no son infinitas, pudiéndose escapar, como de hecho sucede, multitud de supuestos sin incorporar y continuando el socio en esa situación de desprotección primigenia.

En este sentido, partiendo de la posibilidad que tienen los socios de introducir causas de separación en los estatutos que los rigen, cabría en nuestra opinión la lícita configuración estatutaria de un derecho de separación por justa causa, procediendo ésta cuando aconteciesen "importantes motivos" o "infracciones reiteradas y graves del deber de fidelidad entre los socios" ${ } 55$. Esta cláusula obligaría a respetar los deberes de lealtad y fidelidad del socio, ya no sólo frente a la sociedad, sino también frente a los consocios, de tal forma que si estos últimos son infringidos por la mayoría sería posible reconocer el derecho del socio afectado a separarse de la sociedad cuando por exigencias de la buena fe no resulte exigible al socio su continuación en la sociedad.

54 Para un comentario sobre esta sentencia, véase Echebarría Saenz, JA. 1997. El derecho de separación del socio en la SRL (comentario a la STS de 10 de febrero 1997). Revista de Derecho de Sociedades. 9:390-402.

55 Fernández del Pozo, L. p. 280: “A pesar de la dicción literal del RRM cuando exige la determinación concreta y precisa de las causas estatutarias de separación (cfr. Art. 207.1 RRM), la mejor doctrina es del parecer que ello no significa un obstáculo para su admisibilidad so pretexto del carácter genérico o impreciso". Vid. la bibliografía citada por el autor en esa nota de su trabajo. 


\section{Bibliografia}

Alcalá Díaz, MA. 1997. El conflicto de intereses socio-sociedad en las sociedades de capital. Revista de Derecho de Sociedades. 9:89 y ss.

Alfaro Águila-Real, J. 1995. Interés social y derecho de suscripción preferente. Madrid. p. 23. 1996. Conflictos intrasocietarios (Los justos motivos como causa legal no escrita de exclusión y separación de un socio en la sociedad de responsabilidad limitada). Revista de Derecho Mercantil. 222:1133.

2005. Los problemas contractuales en las sociedades cerradas. Indret: Revista para el análisis del Derecho. 4:3.

Alonso Ledesma, C. 2013. La autonomía de la voluntad en la exclusión y separación de socios. Revista de Derecho Mercantil. 287:91.

Brenes Cortés, J. 1999. El derecho de separación del accionista. Madrid.

.2011. El derecho de separación, principales novedades tras las últimas modificaciones operadas en el derecho de sociedades. Revista de Derecho de Sociedades. 37:31-32.

2017. El derecho de separación en caso de falta de distribución de dividendos:

la entrada en vigor del controvertido artículo 348 bis de la Ley de Sociedades de Capital. Revista de Derecho Mercantil. 305:50 y ss.

Cañabate Pozo, R. 2017. La defensa del socio minoritario por falta de distribución de dividendos. Revista de derecho de Sociedades. 50:171 y ss.

Carlón, L. 1978. Reflexiones sobre la tutela de la minoría en la Sociedad de responsabilidad limitada. In Estudios de Derecho Mercantil en homenaje a Rodrigo Uría. Madrid. pp. 83-84. Echebarría Saenz, JA. 1997. El derecho de separación del socio en la SRL (comentario a la STS de 10 de febrero 1997). Revista de Derecho de Sociedades. 9:390-402.

Emparanza, A. 2011. Artículo 346. Causas legales de separación. in Rojo, A, Beltrán, E, editors. Comentarios a la Ley de Sociedades de Capital. Cizur Menor.

Farrando Miguel, I. 1998. El derecho de separación del socio en la Ley de Sociedades Anónimas y la Ley de Sociedades de Responsabilidad Limitada. Madrid.

Fernández del Pozo, L. 2006. La arbitrabilidad de un derecho estatutario de separación por “justa causa” en una Sociedad Anónima. En torno a la STC 9/2005, de 17 de enero de 2005. Revista de Derecho de Sociedades. 26:269-272. 
García Morales E/Jiménez López, L. 2018. ¿Es compatible el artículo 348 bis con las restricciones al reparto de dividendos previstas en determinados contratos de financiación? Diario La Ley. 9150:1-13.

García Sanz, A. 2012. Derecho de separación en caso de falta de distribución de dividendos. Revista de Derecho de Sociedades. 38: 55-71.

García Vicente, JR. 2011. Artículo 128. Reglas de liquidación del usufructo. In Rojo A/ Beltrán, E. Comentarios a la Ley de Sociedades de Capital. Cizur Menor.

Garrigues, J/Uría, R. 1953. Comentario a la Ley de Sociedades Anónimas. Tomo II. Madrid. Ginés Castellet, N. 2013. Impugnación de acuerdos sociales y abuso de derecho: algunas reflexiones para el ordenamiento jurídico español a la luz de la experiencia francesa. Revista de Derecho de Sociedades. 40: 274 y ss.

Girón Tena, J. 1952. Derecho de Sociedades Anónimas (Según la Ley de 17 de julio de 1951). Valladolid.

González Castilla, F. 2012. Reformas en materia de separación y exclusión de socios. In Farrando Miguel, I, González Castilla, F, Rodríguez Artigas, F, editors. Las reformas de la Ley de Sociedades de Capital. Cizur Menor.

Hernando Cebriá, L. 2011. Del socio de control al socio tirano y al abuso de la mayoría en las sociedades de capital. Revista de Derecho de Sociedades. 37:173-205.

Iraculis Arregui, N. 2012. La separación del socio sin necesidad de justificación: por no reparto de dividendos o por la propia voluntad del socio. Revista de Derecho de Sociedades. 38:234. Martí Miravalls, J. 2010. La ampliación del derecho de separación del socio en las sociedades de capital cerradas. In Hierro Anibarro, editor. Simplificar el Derecho de Sociedades. Madrid. p. 496. Martínez Calcerrada, L. 1979. La buena fe y el abuso del derecho. Su respectiva caracterización como límites en el ejercicio de los derechos. Revista de Derecho Privado. 1979:434 y ss.

Martínez Muñoz, M. 2015. El derecho de separación del socio en las sociedades de capital y su regulación en el Anteproyecto de Ley de Código Mercantil. CEF Legal: Revista Práctica de Derecho. 175-176:29-34.

Martínez Sanz, F. 1997. La separación del socio en la sociedad de responsabilidad limitada. Madrid. pp. 3-4.

Motos Guirao, M. 1956. La separación voluntaria del socio en el Derecho Mercantil español. Revista de Derecho Notarial. 11:81-83. 
Pulgar Ezquerra, J. 2013. Reestructuración de sociedades de capital y abuso de minorías. Revista de Derecho Bancario y Bursátil. 129:29-34.

. 2017. Reparto legal mínimo de dividendos: protección de socios y acreedores (solvency test). Revista de Derecho Bancario y Bursátil. 147:143-144.

Paz-Ares, C. 2006. La sociedad en general: caracterización del contrato de sociedad. In Uría, R, Menéndez, A. Curso de Derecho Mercantil. Tomo I. Cizur Menor.

Rodas Paredes, P. 2013. La separación del socio en la Ley de sociedades de capital. Madrid. Sánchez Ruiz, M. 2000. Conflictos de Intereses entre Socios en Sociedades de Capital. Elcano. Sequeira Martín, A. 2011. Derecho de separación y la exclusión del socio. Revista de Derecho de Sociedades. 36:190.

Silva Sánchez, MJ/Sambeat Sastre, JM. 2012. Análisis y crítica del artículo 348 bis de la Ley de Sociedades de Capital. Diario La Ley. 7844:3.

Vázquez Lépinette, T. 2012. La separación por justa causa tras las recientes reformas legislativas. Revista de Derecho Mercantil. 283:184.

Velasco Alonso, A. 1976. El derecho de separación del accionista. Madrid.

Vela Torres, PJ. 2013. El derecho de separación del socio en las sociedades de capital: una reforma incompleta y parcialmente fallida. Derecho de los Negocios. 268:55.

SOBRE O AUTOR:

Miguel Martínez Muñoz

Profesor de Derecho Mercantil en Universidad Pontificia Comillas ICAI-ICADE

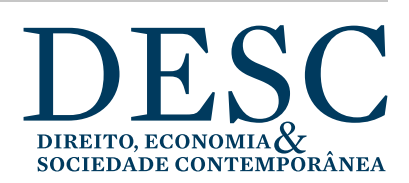

